\title{
Programa de acceso ampliado a terapia anti retroviral en Chile, Plan Auge y Cohorte Chilena de SIDA: Tres iniciativas complementarias
}

\author{
MARCELO WOLFF R. y CARLOS BELTRÁN B.*
}

\author{
Expanded Access Program to Anti Retroviral Therapy in Chile, Auge \\ Protocol and Chilean AIDS Cohort: Three complementary initiatives
}

El desarrollo de terapia anti retroviral efectiva ha tenido resultados dramáticos en la disminución de la morbimortalidad por SIDA y ha trasformado esta infección desde una enfermedad rápidamente letal a una patología crónica, polimorfa, grave, requirente de tratamiento complejo, de alto costo y muchas veces tóxico pero aún así, manejable. Los países desarrollados han implementado esta modalidad terapéutica masivamente en su población infectada en seguimiento con resultados muy favorables.

Los países subdesarrollados, donde la epidemia alcanza proporciones inmensas y donde está la mayoría de la población infectada (> 90\%) no han podido implementar programas de atención amplios por falta de recursos para comprar los fármacos, pobre estructura sanitaria, falta del recurso humano calificado necesario para llevarlo a cabo y muchas veces graves problemas sociales y políticos. Estos países, muy en especial en Africa, dependen totalmente del mundo desarrollado tan sólo para considerar el inicio de un programa terapéutico amplio. Afortunadamente hay conciencia y consenso que esto debe hacerse. Países de recursos medios, entre los que destaca en forma pionera Brasil, y a los que se han sumado muchos países del resto de América Latina pero que también incluye algunos países asiáticos y de Europa del este, han iniciado programas de acceso ampliado a terapia para su población infectada, financiado mayoritariamente con recursos propios. Chile es uno de ellos.

\section{Programa de acceso expandido a terapia anti retroviral}

Chile, país de recursos medios y con una epidemia de moderadas proporciones ha tenido diversos programas de acceso a terapia anti retroviral para la población beneficiaria de la salud pública, con diversos grados de potencia y cobertura: a principios de los años 90 se inició con acceso a monoterapia (zidovudina) de acuerdo a los medicamentos disponibles y a los criterios terapéuticos de la época; a mediados de la década se amplió esta cobertura a regímenes de dos antiretrovirales y con una cobertura que llegaba a menos del $50 \%$ de la población. Esa época fue la de mayor tensión y desgaste emocional para los equipos tratantes, que debían decidir a quién dar tratamiento entre una población mucho mayor que las terapias disponibles y con igual necesidad terapéutica. Tal como se había visto en otras partes esos esquemas terapéuticos sólo lograban moderado y temporal impacto en morbimortalidad, lo que fue objetivado en el país ${ }^{1}$ y llevó a la Sociedad Chilena de Infectología a pronunciarse respecto a su inconveniencia y a recomendar la ampliación de cobertura y poten$\mathrm{cia}^{2}$, a la luz del conocimiento contemporáneo

* Coordinadores Grupo SIDA Chile. 
(1995-6) de la mucho mayor eficacia de la terapia anti retroviral de alta efectividad, con al menos 3 medicamentos de más de una familia farmacológica. Por un tiempo la autoridad sanitaria empezó a otorgar terapias más completas, pero manteniendo una fracción de ellas con eficacia subóptima (biterapia). A fines del año 2001 el Ministerio de Salud, implementando lo que pasaba a ser una política de Estado, decidió otorgar terapia anti retroviral moderna sin costo para los beneficiarios de la salud pública, con la meta de alcanzar una cobertura de $100 \%$ para la población con necesidades del tratamiento al más breve plazo. El programa ha sido básicamente financiado con recursos generados en la nación y primero incorporó a todos los pacientes en biterapia a terapia moderna y luego empezó a incorporar nuevos pacientes previamente no tratados. La situación actual es que el programa de acceso expandido a terapia antiretroviral ha alcanzado una cobertura de prácticamente $100 \%$ en los pacientes beneficiarios de la salud publica que la requieren (75-80\% del total en seguimiento) con cerca de cinco mil pacientes en tratamientos y una tasa de incorporación de 100 a 120 pacientes nuevos por mes, incluidos los ajustes de terapias previamente aprobadas en aquellos que hayan tenido toxicidad a los medicamentos o fracaso terapéutico. El programa se ha implementado a través de la Comisión Nacional de SIDA (CONASIDA). Esta institución coordinó la elaboración de guías terapéuticas nacionales por parte de expertos locales que dan fundamentalmente respuesta y orientación a cuándo empezar, con qué, cómo monitorear y cuándo parar o cambiar el tratamiento ${ }^{3}$. Hay 32 centros de atención pública de pacientes infectados por VIH a lo largo del país en todos los servicios de salud; estos están constituidos por equipos multidisciplinados, de tamaño variable, que incluyen al menos médicos y enfermeras o matronas pero que pueden incluir además a psicólogos, asistentes sociales, químico-farmacéuticos y odontólogos. Un 30\% de los médicos tratantes son especialistas infectólogos o inmunólogos y el $70 \%$ restante, internistas, dermatólogos o médicos con formación general. Dos terceras partes de los pacientes están en la Región Metropolitana, donde casi todos los centros cuentan con especialistas. Los médicos tratantes deciden un régimen terapéutico específico y lo solicitan en forma individualizada por paciente a CONASIDA; las solicitudes son analizadas por un equipo asesor y aprobadas, modificadas, diferidas para mayor información o rechazadas. Una vez aprobadas, CONASIDA emite la autorización y orden de despacho a las diferentes compañías farmacéuticas a los centros de atención, los que deben llevar el correspondiente registro de terapias aprobadas y en uso. No hay un stock de uso libre de medicamentos sino medicamentos con destino personalizado. Una vez iniciada la terapia se procede al despacho periódico de medicamentos a cada centro. En casos de ajustes necesarios por toxicidad o fracaso se usa el mismo sistema de solicitud, revisión y aprobación. El sistema sólo utiliza medicamentos originales y no genéricos. Los médicos deben basarse en las guías nacionales para hacer su elección de medicamentos, pero son libres de usar la combinación farmacológicamente adecuada que más les parezca conveniente, con mínimas restricciones, y elegir entre 10 anti retrovirales disponibles. De los medicamentos autorizados en el país sólo la combinación lopinavir/ritonavir no está autorizada como terapia inicial. Además de proporcionar los anti retrovirales, el programa tiene dos aportes adicionales: exámenes y presupuesto adicional para fármacos no anti retrovirales. El recuento de linfocitos CD4 y la carga viral, tanto para la evaluación de la enfermedad general así como para determinar la necesidad de inicio del tratamiento y monitoreo del mismo, se realizan en dos centros en el país y no tienen restricciones pero sí recomendaciones provenientes de las mismas guías. Bajo condiciones especiales el programa también otorga la realización del estudio de genotipificación, que permite la detección de mutaciones en diferentes codones del virus, responsables de la generación de resistencia a anti retrovirales específicos.

Por otra parte, el Fondo Nacional de Salud, FONASA, entrega presupuestos adicionales a los distintos centros de atención para la compra de medicamentos utilizados en infecciones y tumores oportunistas asociados a la infección por VIH, así como para el manejo de complicaciones de la terapia. Este presupuesto adicional no tiene un límite fijo en general pero requiere una estricta justificación de uso para las condiciones previamente definidas en este subprograma. El resto de los costos de atención deben ser asumidos por los centros respectivos. Hasta septiembre del 2004 había 4.453 pacientes que iniciaron su terapia bajo esta modalidad, equivalentes prácticamente al $100 \%$ de los pacientes beneficiarios de salud pública que lo necesitan. La atención pública ha absorbido el $75 \%$ de los pacientes con infección por VIH en el país. Los beneficios de este programa no se aplican a los pacientes no beneficiarios, es decir pacientes sin cobertura médica y no indigentes o los afiliados a las ISAPRES. 


\section{Plan Auge}

La reforma sanitaria y la implementación inicial del Plan Auge (Acceso Universal de Garantías Explícitas) han tenido directa influencia en el programa de terapia antiretroviral en el país. Desde abril del 2004 la infección por VIH fue incorporada como una de las patologías con garantías explícitas de atención dentro del sistema público de salud ${ }^{4}$. Esto significa asegurar la terapia anti retroviral para todos los niños y mujeres embarazas infectados que la requieran y para los adultos con necesidades de tratamiento. Estipula explícitamente que los medicamentos deben estar disponibles ya sea para terapias iniciales o modificaciones, en un plazo de 40 días desde su solicitud a CONASIDA. Este plan también define las características en infraestructura y recursos materiales con que deben atenderse los pacientes y al personal requerido para la atención, con un número de horas funcionarias (médicos, enfermeras, químicos farmacéuticos) especificados de acuerdo al número de pacientes en atención. El plan estipula que los pacientes tienen derecho a exigir el cumplimiento de estos compromisos. Esto ha significado que al programa de acceso expandido se le han puesto exigencias y plazos que previamente no existían. La ley establece que a corto plazo estas garantías explícitas en funcionamientos para los pacientes del sistema publica se empiecen a aplicar también a los afiliados a ISAPRES.

\section{Cohorte Chilena de SIDA}

Una vez iniciada la implementación del programa de acceso ampliado, los equipos tratantes vieron la oportunidad de evaluar sistemática y homogéneamente su impacto, en el entendido que la autoridad sanitaria no tenía la capacidad de hacer esta evaluación en forma completa y detallada. Así, y a iniciativa del Comité Consultivo de SIDA de la Sociedad Chilena de Infectología, se creó el Grupo SIDA-Chile con la participación de los equipos tratantes de los centros públicos de atención de la enfermedad por VIH y con el objetivo de evaluar los resultados del programa en el país en términos de morbimortalidad, impacto en las enfermedades marcadoras de SIDA, toxicidad, tendencia en uso de medicamentos y adherencia a terapia, entre otros. Los equipos participantes deben incorporar a todos los pacientes que hayan iniciado terapia bajo esta modalidad y con un seguimiento relativamente homogéneo y estandarizado. Los pacientes incor- porados en este seguimiento conforman la Cohorte Chilena de SIDA. Hasta septiembre del 2004 se ha logrado reclutar 29 de 32 centros (90\%) y la incorporación de 4.365 de los 4.453 pacientes con terapias iniciadas $(98 \%)$. Con un respaldo del Fondo Global para la Lucha contra el SIDA, Tuberculosis y Malaria, se estableció una oficina central administrativa de la cohorte con dos médicos, una enfermera universitaria, una secretaria y un asesor computacional, además del equipamiento correspondiente. Hay dos médicos coordinadores del grupo SIDA-Chile y un directorio de 7 miembros. La cohorte tiene un portal de internet (www.sidachile.cl), todos los participantes tienen correos electrónicos propios y los datos se intercambian a través de la red. El número total de participantes es de 80 personas a lo largo de todo el país. A septiembre de 2004 se tiene información basal de 4.365 pacientes y seguimiento por seis meses de 1.075. Se han generado publicaciones en congresos nacionales e internacionales ${ }^{5-9}$ y se estima que no hay otra cohorte con un número tan completo en relación a la población total y que probablemente ésta es una de las mayores cohortes de terapia anti retroviral implementada en un país de recursos medios.

En suma, en Chile tres situaciones han permitido enfrentar la epidemia de SIDA exitosamente desde un punto de vista terapéutico: un programa de acceso ampliado a tratamiento, con terapias de acuerdo a los estándares internacionales, con cobertura para la gran mayoría de la población y que incluye el adecuado monitoreo y aporte de medicamentos adicionales asociados al manejo de la infección por $\mathrm{VIH}$; un marco legal que obliga al sistema de salud a otorgar la atención necesaria y con plazos definidos $y$, finalmente, una organización no gubernamental, nacional y cooperativa, estrechamente asociada al programa, que está actualmente entregando los datos de miles de pacientes en tratamiento para evaluar el impacto del programa e incluso la implementación de éste.

El primer componente se ha empezado a aplicar cada vez más en otros países y es posible que el segundo, con el mismo marco legal u otro, también se aplique en varios de ellos. Pero sin lugar a dudas, el tercero, la Cohorte Chilena de SIDA y sus actuales 4.365 pacientes, es una iniciativa única que está aportando información no sólo útil para el país sino también para otros similares que estén implementando, o en vías de hacerlo, este programa absolutamente justificado desde el punto de vista médico, moral, social e incluso económico de acceso universal a terapia 
para pacientes infectados por VIH. Claramente la implementación del programa, su marco legal y el mecanismo de evaluación estarán dentro de los objetivos sanitarios que a futuro se estimarán como correctos, oportunos y exitosos.

\section{Referencias}

1.- Wolff M, Diomedi A, Dabanch J, Bidart, Bustamante C, Morales O y Northland R. Seguimiento prospectivo de una población infectada por VIH con y sin posibilidades de terapia antiretroviral: impacto en sobrevida y complicaciones (EFITAR). Rev Méd Chile 2001; 129: 886-94

2.- Sociedad Chilena de Infectología, Comité Consultivo de SIDA. (Wolff M. coordinador). Terapia anti retroviral. Rev Méd Chile 1998; 126: 577-81

3.- CONASIDA. Ministerio de Salud. Guía clínica para la atención de las personas adultas que viven con VIH/ SIDA. 2001

4.- Ministerio de Salud. Tratamiento antiretroviral para personas que viven con VIH/SIDA y prevención de la transmisión vertical del VIH. www.minsal.cl. Acceso el 23/10/2004.

5.- Wolff M, Beltrán C, Gallardo D, Daube E; for the ChiAC group and CONASIDA. A National Antiretroviral Therapy (ART) Expanded-Access-Program (EAP) and the Chilean AIDS Cohort (ChiAC): a Model for ART in a Middle-income Country. Abstract $\mathrm{H}$ 855. 43th Interscience Conference on Antimicrobial Agents and Chemotherapy (ICAAC), Chicago, E.U.A., Septiembre 2003

6.- Vásquez P, Beltrán C, Gallardo D, Bustos $\mathrm{M}$, and the Chilean AIDS Study Group. Efficacy of HAART in patients with extremely advanced HIV disease in a middle income country. (Late breaker).9th European AIDS Conference, Varsovia, Polonia, Octubre 2003.

7.- Wolff $\mathrm{M}$, Beltrán $\mathrm{C}$, de Andraca $\mathrm{M}$ and the Chilean AIDS cohort. Tuberculosis in the general and HIV population in Chile: clinical and epidemiological comparison and the effect of ART. $11^{\text {th }}$ Conference on Retrovirus and Opportunistic Infections (CROI). Abstract 758. San Francisco, E.U.A., Febrero 2004.

8.- Beltrán C, Wolff $\mathrm{M} \mathrm{J}$, Morales R, Chahin $\mathrm{C}$ for the Chilean AIDS Cohort. A national cohort model for assessing the effect of EAP for ART and the short term predictors of efficacy in a middle-income country. $11^{\text {th }}$ Conference on Retrovirus and Opportunistic Infections (CROI). Abstract 758. San Francisco, E.U.A, Febrero 2004

9.- Wolff M J, Beltrán C, Ayala, M, Jenssen W, Hering M, National AIDS Commission (CONASIDA); Chilean AIDS Cohort (ChiAC) Study Group.Trends in Antiretroviral (ARV) Drug use in a Middle-Income Country with an Expanded Access Program (EAP) to HAART. Abstract 890. 42nd Annual Meeting of the Infectious Diseases Society of America (IDSA), Boston, E.U.A., Septiembre 30- Octubre 3, 2004.

Correspondencia a:

Marcelo Wolff Reyes

mwolff@vtr.net

marcelowolff@yahoo.com 